\title{
Ostracod valves as efficient UV protection
}

\author{
Lynn VAN DEN BROECKE, ${ }^{1,2 *}$ Koen MARTENS, ${ }^{1,2}$ Valentina PIERI, ${ }^{1}$ and Isa SCHÖN1 \\ ${ }^{1}$ Royal Belgian Institute of Natural Sciences, Freshwater Biology, Vautierstraat 29, 1000 Brussels, Belgium; ${ }^{2}$ University of Ghent, \\ Biology, Ledeganckstraat 35, 9000 Gent, Belgium \\ *Corresponding author: lynn.vandenbroecke@naturalsciences.be
}

\begin{abstract}
One of the major consequences of climate change is the increase of ultraviolet radiation, especially UVB (280-315 $\mathrm{nm})$. This has important consequences for organisms and ecosystems. In surface freshwater ecosystems with transparent water, UV can easily penetrate deeply. Here, we used three different experimental approaches to examine the response of non-marine ostracods and cladocerans to UVB radiation: estimating lethal doses, determining how much UVB is blocked by the valves, and analysing valve chemical compositions. For most investigated crustaceans, we found a strong correlation between the amount of UVB that is blocked by the valves and the lethal UVB doses. Most ostracod valves blocked between $60 \%$ and $80 \%$ of UVB radiation, thus providing effective shielding. Pigmented species from temporary habitats were best protected. These species also showed high lethal UVB doses of $110 \mathrm{~kJ} \mathrm{~m} 2$ to $214 \mathrm{~kJ} m 2$. In the waterflea Daphnia magna, valves only stopped ca 35\% of UVB radiation, and the lethal dose was half that of the doses estimated for ostracods. Since there were no significant differences in chemical composition of the valves between the investigated species, other factors must be responsible for the observed differences, which remain to be identified.
\end{abstract}

Key words: climate change, UV, Ostracoda, Daphnia, valve.

Received: September 2011. Accepted: December 2011.

\section{INTRODUCTION}

The increase of ultraviolet radiation, and in particular of UVB (280-315 nm), is one of the major effects of climate change. Ultraviolet radiation reaching the Earth's surface has significantly increased since 1979 at all latitudes, except for the equatorial zone (Herman 2010). This has important consequences for organisms and ecosystems (Harley et al. 2006; Nelson et al. 2006) as there is increasing evidence that both normal and enhanced levels of UVB radiation cause biological damage and can have harmful effects on the biosphere (Zepp et al. 2007).

Biological protection from UVB radiation can be achieved by specific responses, such as improved cell-repair mechanisms (Blaustein, and Belden 2003), photoprotective compounds or UV-absorbing substances (Sinha et al. 2007), which seem to be widespread in nature (Oren, and Gunde-Cimerman 2007).

Current literature has mainly focused on the UV effects in marine environments, particularly the Antarctic, where ozone depletion has been most dramatic (McKenzie et al. 2007). Less information is available for freshwater ecosystems, and there is only a limited number of studies evaluating the effects of UVB radiation on invertebrates in general (Cywinska et al. 2000; Bonaventura et al. 2005; Ruelas et al. 2006; Nahon et al. 2009) and crustaceans in particular (Macfadyen et al. 2004; Obermüller et al. 2007).

The effects of UVB on aquatic organisms are mainly dependent on the radiation dose reaching the organisms, which is influenced by the capacity of UV radiation to penetrate aquatic environments. The latter is mainly determined by water-column depth, dissolved organic carbon, and the quantity of organic and inorganic molecules (Häder et al. 2007), in short the turbidity. In freshwater ecosystems with transparent water, UV radiation can easily penetrate deep, up to $57 \mathrm{~cm}$ (Williamson, and Rose 2010).

Ostracoda or mussel-shrimps are small, bivalved Crustacea. Ostracods are very common in most inland waters, but they also occur in marine, interstitial and even semi-terrestrial environments (Martens et al. 2008). These crustaceans are of great interest as a model group in ecological and evolutionary research, because their calcified valves preserve well as microfossils. Their excellent fossil record thus provides real-time frames for evolutionary processes (Holmes, and Chivas 2002). Ostracods can furthermore serve as proxies for climate and ecosystem changes. In addition, non-marine ostracods are well-suited for investigations on the evolution of sex and parthenogenesis (Martens 1998), because of their variety of reproductive modes.

Here, we investigate the response of non-marine ostracods and cladocerans (as comparison) to UVB radiation, using three different approaches: estimating lethal doses, revealing how much UVB is blocked by the valves of these crustaceans and determining valve chemical compositions. 
Tab. 1. Overview of investigated crustacean species, their pigmentation, reproductive mode and the habitat type of the sample locations.

\begin{tabular}{lcc}
\hline Species & Pigmentation & Location \\
\hline Darwinula stevensoni & No pigmentation & Hollandersgatkreek Lake (Belgium) \\
Eucypris virens & Green & Temporary pond (Belgium) \\
Herpetocypris reptans & Brown & Ria Artegna (Italy) \\
Cypridopsis vidua & Brown/Yellow/Green lines & Rio Bosso (Italy) \\
Bradleystrandesia fuscata & Dark brown & Bài de Dònes Lake (Italy) \\
Heterocypris incongruens & Brown & Temporary pond (Belgium) \\
Candona candida & No pigmentation & River (Mongolia) \\
Tonnacypris lutaria & Green & Temporary pond (Belgium) \\
Daphnia pulex & No pigmentation & Temporary pond (Belgium) \\
Daphnia magna & No pigmentation & Lab culture \\
\hline
\end{tabular}

\section{MATERIALS AND METHODS}

We choose eight ostracod species with calcified carapaces, varying in valve pigmentation and location (Tab. 1). The common cladocerans Daphnia pulex and Daphnia magna with less calcified carapaces and with-out pigmentation were also investigated. All samples were taken with a hand-net of $250 \mu \mathrm{m}$ mesh size. Origin of investigated specimens is given in Tab. 1.

Estimated relative lethal doses

To estimate the relative lethal dose, individual crustaceans were placed in petri dishes with EPA medium $(96$ $\mathrm{mg} \mathrm{L}^{-1} \mathrm{NaHCO} 3,60 \mathrm{mg} \mathrm{L}^{-1} \mathrm{CaSO}_{4} \cdot 2 \mathrm{H}_{2} \mathrm{O}, 123 \mathrm{mg} \mathrm{L}^{-1}$ $\mathrm{MgSO}_{4} .7 \mathrm{H}_{2} \mathrm{O}, 4 \mathrm{mg} \mathrm{L}^{-1} \mathrm{KCl}$ and $\mathrm{pH}$ 7.4-7.8). Depending on their size, four (for the ostracods $H$. incongruens, $E$. virens, T. lutaria and the cladocerans $D$. pulex and $D$. magna) or six (the ostracod D. stevensoni) biological replicas, respectively, were conducted in individual Petri dishes. Crustaceans were put on ice and were exposed to UVB from a $6 \mathrm{~W}$ Vilber Loumat UV lamp $(\lambda=312 \mathrm{~nm})$ with an intensity of $680 \mu \mathrm{W} \mathrm{cm}{ }^{-2}$ at a distance of approximately $15 \mathrm{~cm}$ to the lamp. We exposed the individuals once to a high (lethal) dose of several hours and did not spread exposure over several days.

Every half hour, the state of the crustaceans (alive or dead) was recorded and based on these observations, the (approximate) lethal dose was determined. Differences in lethal doses were tested with One-Way ANOVAs and the chi-square test in STATISTICA ${ }^{\circledR}$ for their significance.

\section{UV protection of valves}

We also estimated how much UV could penetrate through crustacean valves of the species $D$. stevensoni, $E$. virens, $H$. reptans, $H$. incongruens, $T$. lutaria, $C$. vidua, B. fuscata, C. candida, and D. magna. After removing the valves from the soft parts, valves were put next to each other on a cover glass in a way that they cover the UVB sensor of the UVP radiometer. Because the surface of the UVB sensor is about $0.8 \mathrm{~cm}^{2}$ and ostracod valves are rather small, we decreased the surface to $7 \mathrm{~mm}^{2}$ with white paper. We first confirmed that the paper used blocked UVB effectively. Next, single crustacean valves (between 5 and 50 valves, depending on the size) were arranged on a microscopic cover glass in a way that the UVB sensor surface was maximally covered. Then the cover glass was placed on the UVB sensor of the UVP radiometer. Because of the shape of the valves it was not possible to cover the entire UVB sensor. Therefore, after each exposure experiment, a photograph of the cover glass with the valves was taken with a Leica ${ }^{\circledR}$ camera. We then estimated the amount of gaps that the valves could not cover on the UVB sensor with the program Image J (Girish, and Vijayalakshmi 2004), and used these data to recalculate the UV blockage as if the UVB sensor was covered $100 \%$ by the valves. UVB intensity $\left.(\mu \mathrm{W} \mathrm{cm})^{-2}\right)$ was measured three times while the valves covered the UVB sensor (every time in another arrangement on the cover glass) and three times with the cover glass only without valves. The correlation between the estimated relative lethal dose and de UVB blocked by the valves was calculated in Excel and tested for its significance in XLSTAT $^{\circledR}$. Statistical analyses of UV protection between the investigated crustaceans were accomplished with OneWay ANOVAs and chi-square tests in STATISTICA ${ }^{\circledR}$.

Valve chemical composition

The relative chemical composition of valves was determined for all ostracod species and the cladoceran $D$. magna. Valves were taken from the UV protection experiment (see 2.2 above) and broken into two pieces, to conduct X-ray microanalysis (EDAX) at the cracked valve area.

For each species, three different valves were examined for their relative chemical composition and measurements of chemical composition were conducted at three different points for each valve. In order to reduce most of the carbonate background of the stub, measurements were taken in the middle of the cracked valve area. The Spectrum Genesis software (EDAX) was used to obtain the chemical composition spectrum from the X-ray analysis; the amount of each chemical element was calculated in per- 
centage. Based on the data from the point analyses, the mean percentage of each element and its standard deviation was calculated. Differences in chemical composition were tested with One-Way ANOVAs and chi-square tests in STATISTICA ${ }^{\circledR}$ for their significance.

\section{RESULTS}

The lethal UVB dose of the six investigated crustacean species varied considerably (Tab. 2): for Tonnacypris lutaria the lethal dose was $214 \mathrm{~kJ} \mathrm{~m}^{-2}$, for Eucypris virens $166 \mathrm{~kJ} \mathrm{~m}^{-2}$, for Darwinula stevensoni $130 \mathrm{~kJ} \mathrm{~m}^{-2}$, and for Heterocypris incongruens $110 \mathrm{~kJ} \mathrm{~m}^{-2}$. These lethal doses for the 4 ostracods were significantly different from each other $(p<0.005)$. The lethal dose for D. stevensoni was significantly lower than the doses of $E$. virens and T. lutaria $(p<0.0005)$, but significantly higher than the lethal dose of $H$. incongruens $(p<0.0005)$.

The screened cladocerans displayed significantly lower lethal doses $(p<0.005$ for both cladocerans): we observed $51 \mathrm{~kJ} \mathrm{~m}^{-2}$ for D. magna and $15 \mathrm{~kJ} \mathrm{~m}^{-2}$ for Daphnia pulex.

Our second experiment revealed that crustacean valves provide considerable protection against UVB (Fig. 1). The valves of the examined species can be divided into four different groups, which differed significantly from each other $(p<0.05)$. In the first group with $E$. virens, H. incongruens, $H$. reptans and T. lutaria, valves blocked about $80 \%$ of the UVB radiation. For the second group (containing $C$. vidua, B. fuscata and C. candida), valves provided almost as much protection as $70 \%$ of UVB were blocked, but this difference was significant. The third group consisted of $D$. stevensoni where valves blocked $60 \%$ of UVB. The fourth group, $D$. magna, was with $35 \%$ the least protected.

Pigmented species (E. virens, H. reptans, C. vidua, $B$. fuscata, $H$. incongruens and T. lutaria; see also Tab. 1) were significantly $(p<0.05)$ better protected than species without pigmentation (D. stevensoni, $C$. candida and Daphnia magna). Also the habitats from which our samples came (Tab. 1) had a significant effect on UVB blockage $(p<0.001)$ as ostracods from temporary habitats appeared to be more protected.

We observed a positive correlation $\left(\mathrm{R}^{2}=0.94 ; p=0.05\right)$ between the UVB protection of the valves and the estimated lethal doses for the ostracod species $E$. virens, $T$. lutaria, D. stevensoni and the cladoceran D. magna; $\mathrm{R}^{2}$ is only 0.62 and not significant $(p=0.154)$ when $H$. incongruens is included in the statistical correlation analyses.

To examine whether specific chemical elements in the valves could influence how much UVB is blocked, we also analysed the relative valve chemical composition. We found that all investigated valves, also the ones from the cladoceran Daphnia magna (Tab. 3), consisted to almost $100 \%$ of calcium carbonate although D. magna valves contained a lower percentage of $\mathrm{Ca}$ than the ostracod valves. The other components $(\mathrm{Na}, \mathrm{Mg}, \mathrm{Cl}, \mathrm{S}$ and $\mathrm{K})$ were found
Tab. 2. Lethal dose of UVB estimated for four ostracod species, Daphnia pulex and D. magna.

\begin{tabular}{lc}
\hline Species & Lethal dose $\left(\mathrm{kJ} \mathrm{m}^{-2}\right)$ \\
Tonnacypris lutaria & 214 \\
Eucypris virens & 166 \\
Darwinula stevensoni & 130 \\
Heterocypris incongruens & 110 \\
Daphnia magna & 51 \\
Daphnia pulex & 15 \\
\hline
\end{tabular}

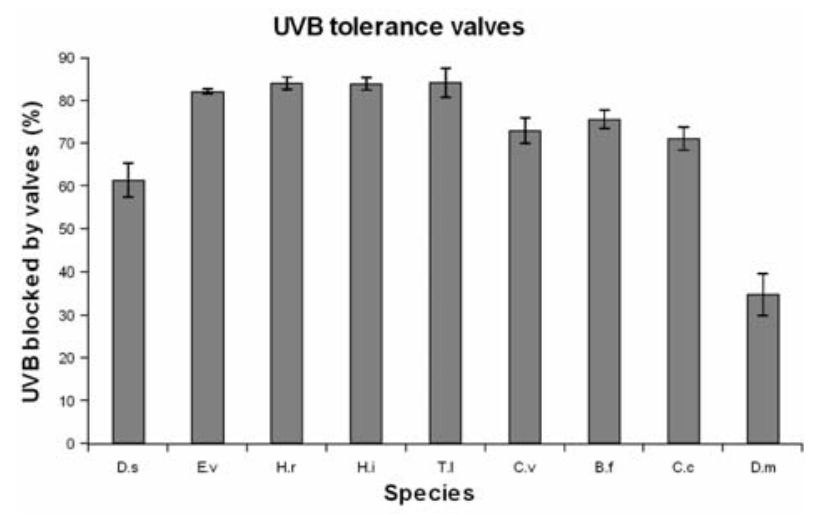

Fig. 1. D.s. Darwinula stevensoni, E.v. Eucypris virens, H.r. Herpetocypris reptans, H.i. Heterocypris incongruens, T.1. Tonnacypris lutaria, C.v. Cypridopsis vidua, B.f. Bradleystrandesia fuscata, C.c. Candona candida, D.m. Daphnia magna.

in very small amounts of less than $1 \%$ in total. We did not observe any significant differences in the chemical composition between the investigated crustacean species (Tab. 3 ).

\section{DISCUSSION}

We found that valves can provide effective UV protection in freshwater crustaceans. Nevertheless, the relative lethal UVB doses differed considerably between the investigated species.

Sensitivity to UVB depends on the length, duration, and type of exposure. These factors varied between our study and those of others. For example, Hurtubise et al. (1998) and Fischer et al. (2006) exposed the animals for shorter periods over several days and then calculated the total doses. According to Hurtubise et al. (1998), Heterocypris incongruens can survive a daily dose of $16 \mathrm{~kJ} \mathrm{~m}^{-2}$ for 7 days, resulting in a total dose of $114 \mathrm{~kJ} \mathrm{~m}^{-2}$. This is almost the same relative lethal dose as we estimated for $H$. incongruens in our experimental setup during a shorter, but continuous, exposure period of $5 \mathrm{~h}$.

Also our relative estimates of the lethal dose for Daphnia magna and Daphnia pulex are comparable with lethal doses for $D$. magna determined by others $\left(\mathrm{LD}_{50}=13 \mathrm{~kJ} \mathrm{~m}^{-2}\right)$ (Fischer et al. 2006), while D. carinata $\left(\mathrm{LD}_{50}=35 \mathrm{~kJ} \mathrm{~m}^{-2}\right), D$. pulex obtusa (with dark pigmentation; $\mathrm{LD}_{10}=63 \mathrm{~kJ} \mathrm{~m}^{-2}$ ) and D. galeata $\left(\mathrm{LD}_{50}=35 \mathrm{~kJ} \mathrm{~m}^{-2}\right)$ showed a higher tolerance to 
Tab. 3. Relative chemical composition of the valves - major components. Mean percentages (\%) with standard deviations and statistical comparisons for the three most important elements (Carbon, Calcium and Oxygen). Mean percentages per species were calculated from the point analyses of the three valves. There was no significant difference in the $\%$ of the three most common elements between the analysed crustacean species.

\begin{tabular}{|c|c|c|c|}
\hline Species p-value & $\begin{array}{c}\text { Carbon }(\mathrm{C}) \\
p=0.0524\end{array}$ & $\begin{array}{c}\text { Calcium }(\mathrm{Ca}) \\
p=0.1835\end{array}$ & $\begin{array}{c}\text { Oxygen }(\mathrm{O}) \\
p=0.3150\end{array}$ \\
\hline Darwinula stevensoni & $23.59 \pm 5.74$ & $48.10 \pm 15.89$ & $24.90 \pm 3.12$ \\
\hline Eucypris virens & $15.32 \pm 3.12$ & $49.52 \pm 11.41$ & $32.69 \pm 8.03$ \\
\hline Herpetocypris reptans & $20.32 \pm 5.88$ & $58.30 \pm 8.87$ & $18.90 \pm 7.56$ \\
\hline Cypridopsis vidua & $16.90 \pm 2.12$ & $58.33 \pm 9.58$ & $21.76 \pm 7.75$ \\
\hline Bradleystrandesia fuscata & $28.75 \pm 5.56$ & $41.96 \pm 0.43$ & $26.97 \pm 4.43$ \\
\hline Heterocypris incongruens & $28.58 \pm 3.39$ & $44.48 \pm 4.95$ & $25.04 \pm 2.98$ \\
\hline Candona candida & $28.10 \pm 7.73$ & $47.33 \pm 6.58$ & $23.59 \pm 1.05$ \\
\hline Tonnacypris lutaria & $25.88 \pm 9.23$ & $50.66 \pm 13.35$ & $20.48 \pm 3.60$ \\
\hline Daphnia magna & $32.85 \pm 1.35$ & $35.64 \pm 8.46$ & $28.18 \pm 7.63$ \\
\hline
\end{tabular}

UVB radiation (Wübben et al. 2001), which is still way below our relative estimates for the ostracods. Our estimate of the relative lethal dose for D. magna was higher than that of Hurtubise et al. (1998). This variation could be due to our different experimental set up or differences in food quality, which are known to influence UVB tolerance of cladocerans (Zellmer 1996). Also respiration rates (Fischer et al. 2006) and temperature (Moresino, and Helbling 2010) can affect the lethal UVB dose.

The high UVB tolerances of $E$. virens and T. lutaria could be related to their green pigmentation although $H$. incongruens, being characterised by brown pigmentation, was significantly less tolerant to UVB than the other ostracods.

The fact that the habitats from which our samples came (Tab. 1) had a significant effect on UVB blockage could be expected as UV penetration depends on the water depth (Booth, and Morrow 2008) and temporary pools are generally shallower than lakes. Interestingly, in our study, the pigmented ostracods from temporary pools are active swimmers and thus require more protection whereas none pigmented species such as Darwinula stevensoni and Candona candida were sampled from lakes where they usually live within or close to the sediment. Cladocerans, on the other hand, might need less protection against UV because their vertical migration patterns could also reduce their exposure to UV (Ringelberg 1999).

Whereas the ostracod species showed relative high lethal UVB doses (between $130 \mathrm{~kJ} \mathrm{~m}^{-2}$ and $214 \mathrm{~kJ} \mathrm{~m}^{-2} \mathrm{re}-$ spectively; Tab. 2) and their valves provided up to $80 \%$ protection against UVB, D. magna's lower relative lethal doses coincided with a UV protection by the valves of only $35 \%$. Thus, there is a positive correlation between the relative lethal UVB dose and the protection against UV by the valves. Our results for $H$. incongruens deviated from this pattern; this is probably the case because the valves of $H$. incongruens blocked $80 \% \mathrm{UVB}$, but this species showed the lowest relative lethal UVB dose of all investigated ostracods.
Giving its putative ancient asexual mode of reproduction, Darwinula stevensoni should be less efficient in removing deleterious mutations introduced by UV than sexual ostracod species. Hence, another puzzling result of our study is the finding that $D$. stevensoni seems to be resistant to relatively high doses of UVB, whereas its valves only provide protection for $60 \%$. Future research should reveal whether this might be due to a more efficient repair of UV-induced mutations as has been postulated before (Schön, and Martens 1998) or whether for example photoprotective components could play an important role.

From our data, it seems that the chemical composition (in terms of relative amount of the most abundant heavy elements) does not play an important role in determining the UVB tolerance of crustacean valves. Even the valves of D. magna, which do not preserve as well as ostracod valves as microfossils, showed a similar relative valve chemical composition as the investigated non-marine ostracods. The results of our chemical analyses are given as relative values; thus, Daphnia valves might have less calcium carbonate in absolute values. Silicate provides protection against UV, for example in bacteria (Phoenix et al. $2001)$, and has also been found in low percentages $(0.06$ to $0.11 \%$ ) in the valves of the ostracod Cytherissa lacustris (Carbonel, and Farmer 1990). Unfortunately, the analytical method used here (EDAX attached to a Scanning Electron Microscope) is not sufficiently precise to detect such low levels of elements and thus we cannot confirm that silicate is present in the valves of the species investigated here.

Additional research is required to identify which factors are responsible for the significantly lower lethal UVB doses of the ostracod $H$. incongruens and the investigated cladocerans (see above). These factors could, for example, be special proteins such as those found in shells of embryonic cysts of Artemia parthenogenetica (Dai et al. 2011), differences in the valve microstructure or varying concentrations of protective components such as mycosporine-like amino acids or carotenoids (Moeller et al. 
2005; McKenzie et al. 2007; Rautio et al. 2009; Sommaruga 2010).

The bioaccumulation of UV-absorbing compounds in the gonads (Green 1959) could be an explanation for the relatively high lethal UVB dose of $D$. stevensoni, which has a pigmented patch above the ovaria. Also antioxidant enzymes and acetylcholinesterase activity have varied in response to UV exposure (Borgeraas, and Hessen 2002; Souza et al. 2010). Finally, age seems to play a role in UVB tolerance of cladocerans (Huebner et al. 2006), probably because it affects valve calcification (Yamada, and Keyser 2009).

\section{CONCLUSIONS}

Crustacean valves thus provide a surprisingly efficient protection against UVB ranging from ca $35 \%$ in the cladoceran D. magna to up to $80 \%$ in some of the ostracod species. These aquatic invertebrates might thus also be protected against (expected) future increase of UV radiation and its biological consequences.

\section{ACKNOWLEDGMENTS}

We thank Claudine Devries-Duchene, and Zohra Elouaazizi for technical support. Ellen Decaestecker is thanked for providing Daphnia magna material and Fabio Stoch for sampling Bradleystrandesia fuscata. This research was funded by the Belgian Federal Science Policy (Belspo WI/36/I03 and MO/36/015) and by the European Marie Curie Fellowship CRYSTAL (PIEF-GA-2009253767).

\section{REFERENCES}

Blaustein AR, and Belden LK. 2003. Amphibian defenses against ultraviolet-B radiation. Evol. Dev. 5:89-97.

Bonaventura R, Poma V, Costa C, and Matranga V. 2005. UVB radiation prevents skeleton growth and stimulates the expression of stress markers in sea urchin embryos. Biochem. Biophys. Res. Commun. 328: 150-157.

Booth CR, and Morrow H. 2008. The Penetration of UV into Natural Waters. Photochem. Photobiol. 65: 254-257.

Borgeraas J, and Hessen DO. 2002. Variations of antioxidant enzymes in Daphnia species and populations as related to ambient UV exposure. Hydrobiologia 477: 15-30.

Carbonel P, and Farmer M. 1990. The chemical composition of the carapace of Cytherissa. Bull. Inst. Géol. Bassin d'Aquitaine 47: 261-266.

Cywinska A, and Crump D, Lean D. 2000. Influence of UV radiation on four freshwater invertebrates. Photochem. Photobiol. 72: 652-659.

Dai L, Chen DF, Liu YL, Zhao Y, Yang F, Yang JS, and Yang WJ. 2011. Extracellular matrix peptides of Artemia cyst shell participate in protecting encysted embryos from extreme environments. Plos One 6: 1-9.

Fischer JM, Fields PA, Pryzbylkowski PG, Nicolai JL, and Neale PJ. 2006. Sublethal exposure to UV radiation affects respiration rates of the freshwater cladoceran Daphnia catawba. Photochem. Photobiol. 82: 547-550.

Girish V, and Vijayalakshmi A. 2004. Affordable image analysis using NIH Image/ImageJ. Indian. J. Cancer. 41: 47.

Green J. 1959. Pigmentation of an ostracod, Heterocypris incongruens. J. Exp. Biol. 36: 575-582.

Häder DP, Kumar HD, Smith RC, and Worrest RC. 2007. Effects of solar UV radiation on aquatic ecosystems and interactions with climate change. Photochem. Photobiol. Sci. 6: 267-285.

Harley CDG, Hughes AR, Hultgren KM, Miner BG, Sorte CJB, Thornber CS, Rodriguez LF, Tomanek L, and Williams SL. 2006. The impacts of climate change in coastal marine systems. Ecol. Lett. 9: 228-241.

Herman JR. 2010. Global increase in UV irradiance during the past 30 years (1979-2008) estimated from satellite data. J. Geophys. Res. 115: D04203.

Holmes JA, and Chivas A. 2002 The Ostracoda: Applications in Quaternary Research. American Geophysical Union, Washington DC: $313 \mathrm{pp}$.

Huebner JD, Young DLW, Loadman NL, Lentz VJ, and Wiegand MD. 2006. Age-dependent survival, reproduction and photorepair activity in Daphnia magna (Straus, 1820) after exposure to artificial ultraviolet radiation. Photochem. Photobiol. 82: 1656-1661.

Hurtubise RD, Havel JE, and Little EE. 1998. The effects of ultraviolet-B radiation on freshwater invertebrates: Experiments with a solar simulator. Limnol. Oceanogr. 43: 1082-1088.

Macfadyen EJ, Williamson CE, Grad G, Lowery M, Jeffrey WH, and Mitchell DL. 2004. Molecular response to climate change: temperature dependence of UV-induced DNA damage and repair in the freshwater crustacean Daphnia pulicaria. Global Change Biol. 10: 408-416.

Martens K. 1998. Sex and Parthenogenesis - Evolutionary Ecology of Reproductive Modes in Non-marine Ostracods. Backhuys Publishers, Leiden: 335 pp.

Martens K, Schön I, and Meisch C. 2008. Global diversity of ostracods (Ostracoda, Crustacea) in freshwater. Hydrobiologia 595: 185-193.

McKenzie RL, Aucamp PJ, Bais A, Björn LO, and Ilyas M. 2007. Changes in biologically- active ultraviolet radiation reaching the Earth's surface. Photochem. Photobiol. Sci. 6: 218-231.

Moeller RE, Gilroy S, Williamson CE, Grad G, and Sommaruga R. 2005. Dietary acquisition of photoprotective compounds (mycosporine-like amino acids, carotenoids) and acclimation to ultraviolet radiation in a freshwater copepod. Limnol. Oceanogr. 50: 427-439.

Moresino RDH, and Helbling EW. 2010. Combined effects of UVR and Temperature on the Survival of Crab Larvae (Zoea I) from Patagonia: The Role of UV-Absorbing Compounds. Mar. Drugs, 8: 1681-1698.

Nahon S, Porras VAC, Pruski AM, and Charles F. 2009. Sensitivity to UV radiation in early life stages of the Mediterranean sea urchin Sphaerechinus granularis (Lamarck). Sci. Total. Environ. 407: 1892-1900.

Nelson GC, Bennett E, Berhe AA, Cassman K, De-Fries R, Dietz T, Dobermann A, Dobson A, Janetos A, Levy M, Marco D, Nakicenovic N, O’Neill B, Norgaard R, Petschel- 
Held G, Ojima D, Pingali P, Watson R, and Zurek M. 2006. Anthropogenic drivers of ecosystem change: an overview. Ecol. Soc. 11(2): 29.

Obermüller B, Puntarulo S, and Abele D. 2007. UV-tolerance and instantaneous physiological stress responses of two Antarctic amphipod species Gondogeneia antarctica and Djerboa forcipes during exposure to UV radiation. Mar. Environ. Res. 64: 267-285.

Oren A, and Gunde-Cimerman N. 2007. Mycosporines and mycosporine-like amino acids: UV protectants or multipurpose secondary metabolites. FEMS Microbiol. Lett. 269: 1-10.

Phoenix VR, Konhauser KO, Adams DG, and Bottrell SH. 2001. Role of biomineralization as an ultraviolet shield: Implications for Archean life. Geology 29: 823-826.

Rautio M, Bonilla S, and Vincent WF. 2009. UV photoprotectants in arctic zooplankton. Aquat. Biol., 7: 93-105.

Ringelberg J. 1999. The photobehaviour of Daphnia spp. as a model to explain diel vertical migration in zooplankton. Biol. Rev. 74: 397-423.

Ruelas DS, Karentz D, Sullivan JT. 2006. Lethal and sublethal effects of UVB on juvenile Biomphalaria glabrata (Mollusca: Pulmonata). J. Invert. Pathol. 93: 192-200.

Schön I, and Martens K. 1998. DNA repair in ancient asexuals - a new solution to an old problem? J. Nat. History, 32: 943948.

Sinha RP, Singh SP, and Häder. 2007 DP. Database on my- cosporines and mycosporine-like amino acids (MAAs) in fungi, cyanobacteria, macroalgae, phytoplankton and animals. J. Photochem. Photobiol. B. Biol. 89: 29-35.

Sommaruga R. 2010. Preferential accumulation of carotenoids rather than of mycosporine-like amino acids in copepods from high altitude Himalayan lakes. Hydrobiologia 648: 143-156.

Souza MS, Balseiro E, Laspoumaderes C, and Modenutti B. 2010. Effect of Utraviolet Radiation on Acetylcholinesterase Activity in Freshwater Copepods. Photochem. Photobiol. 86: 367-373.

Williamson CE, and Rose KC. 2010. When UV Meets Fresh Water. Science 329: 637-639.

Wübben DL, Vareschi E, Hawes I, and Bodeker G. 2001. Differential UVB-sensitivities of five New Zealand fresh-water zooplankton species. N. Z. J. Mar. Freshwater Res. 35: 635645.

Yamada S, and Keyser D. 2009. Calcification of the marginal infold in podocopid ostracods. Hydrobiologia, 638: 213-222.

Zellmer ID. 1996. The impact of food quantity on UV-B tolerance and recovery from UV-B damage in Daphnia pulex. Hydrobiologia 319: 87-92.

Zepp RG, Erickson DJ, Paul ND, and Sulzberger B. 2007. Interactive effects of solar UV radiation and climate change on biogeochemical cycling. Photochem. Photobiol. Sci. 6: 286-300. 